\title{
Congenital Rubella Syndrome - A Major Review and Update
}

\author{
Nure Ishrat Nazme ${ }^{1}$, Manzoor Hussain ${ }^{2}$, Ashith Chandra Das ${ }^{3}$
}

\begin{abstract}
Rubella is a major public health problem which is usually a mild rash illness in children and adults. However, it has devastating systemic consequences when rubella virus crosses the placental barrier and infects fetal tissue resulting in congenital rubella syndrome (CRS). Congenital rubella syndrome is an under-recognized public health problem in Bangladesh and the burden of the disease weighs heavily on patients and society; therefore, routine vaccination and other preventative strategies are strongly encouraged. Extensive surveillance studies should be conducted to eliminate CRS from our country. In this review, we will characterize the epidemiology of CRS; describe the patho-phyisiology, clinical features and laboratory testing for the disease, and discuss measures needed for prevention of rubella and CRS.
\end{abstract}

Keywords: Congenital rubella syndrome; CRS.

Delta Med Col J. Jul 2015;3(2):89 - 95

\section{Introduction}

Rubella is an exanthematous illness characterised by nonspecific signs and symptoms, including transient erythematous and sometimes pruritic rash, post-auricular or suboccipital lymphadenopathy, arthralgia and low grade fever. ${ }^{1}$ It is typically a mild disease with minor morbidity and a few complications. Moreover, 25 - 50 per cent of rubella infections are subclinical. Maternal infection with rubella during pregnancy, especially in the first trimester results in congenital rubella syndrome (CRS) which is an important cause of miscarriage, stillbirth and a series of birth defects like blindness, deafness, congenital heart disease and mental retardation. ${ }^{2}$

\section{Historical background of rubella and CRS}

Little attention was given to the CRS until 1941, when there was a widespread epidemic of rubella in Australia. During this time an Australian ophthalmologist, Sir Norman Gregg, noted a high incidence of congenital cataracts among many of the infants he examined. He disclosed a relationship between rubella during pregnancy and congenital cataracts. Gregg also reported a high incidence of low birth weight, feeding difficulties, congenital heart defects, deafness and a high mortality rate within those infants. ${ }^{3}$ Gregg's work was confirmed by the epidemiologists Swan et al. 2 years later, recording the associations of congenital heart disease, cataracts, deafness, low birth weight, failure to thrive, and meningitis with central nervous system damage. These clinical signs comprise the modern-day congenital rubella syndrome. ${ }^{4}$

1. Classified Child Specialist, Major, CMH, Dhaka Cantonment, Dhaka, Bangladesh.

2. Assistant Professor, Department of Paediatrics, Jalalabad Ragib Rabeya Medical College, Sylhet, Bangladesh.

3. Professor and Head, Department of Paediatric Cardiology, Bangladesh Institute of Child Health, Director, Dhaka Shishu (children) Hospital, Dhaka, Bangladesh.

Correspondence: Dr. Nure Ishrat Nazme. e-mail: nazssmc@gmail.com 
Since its discovery, rubella epidemics occur at 6to 9-year intervals, and major pandemics have occurred every 10 to 30 years. ${ }^{5}$ The last major pandemic of 1963 to 1965, infected an estimated $10 \%$ of all pregnant women, and $30 \%$ of infants from infected mothers. In 1969, the rubella virus was isolated and identified as the specific organism responsible for CRS. ${ }^{6}$ The first vaccine was licensed in the United States that same year, and since then the reduction in congenital infection from rubella has been dramatic and long standing. ${ }^{7}$

\section{Epidemiology of CRS}

Rubella is a worldwide disease, with peak age incidence less than 10 years of age, causing $70 \%$ to $90 \%$ of the adult population to be exposed to rubella and they develop the antibody. Since rubella vaccine licensure in 1969, substantial decline in rubella and CRS have occurred in the United States. ${ }^{8}$ Currently, in the United States the estimated incidence of CRS is less than 2 per 100,000 live births. ${ }^{9}$ Reported cases of CRS in the United Kingdom (UK) declined from about 50 a year $1971-75$ to just over 20 a year 1986-90. ${ }^{10}$ However, rubella outbreaks continue to occur in other parts of the world. The absolute risk of CRS among children born to mothers infected during pregnancy varies greatly depending on the study, ranging from 2.2 per 1,000 live births in Panama, 1.7 in Israel, 1.7 in Jamaica, 1.5 in Singapore, 0.9 in Sri Lanka, 0.7 in Oman, 0.5 in Malaysia and 0.1 in Myanmar. ${ }^{11-16}$

Special surveillance investigations in developing countries in Africa, the Americas, Asia, Eastern Europe and the Eastern Mediterranean have documented incidence rates of CRS ranging from 0.4 to 4.3 per 1,000 live births, which are comparable to and in some cases higher than those seen in industrialized countries in the prevaccine era. ${ }^{16}$

The current WHO position is that there are more than 100,000 CRS cases occurring every year. ${ }^{2}$ WHO reported rubella cases in Bangladesh by year 2003-2010 which was 13,464 in 2009 and 13,125 in 2010 and rubella attack rate among antenatal population in Bangladesh is 14.5 in 1000 during pregnancy. ${ }^{17,18}$ Rubella is often not notified; consequently, rubella outbreaks can occur without clinical recognition. Thus, the estimated incidence of CRS defects is likely less than the true incidence. ${ }^{19}$

\section{Pathogenicity}

Rubella is a member of the togaviridae. The virus contains single-stranded RNA. It enters the cell via endocytic pathway. Viral replication continues in localized areas of the nasopharynx and regional lymph nodes for 7-9 days and is followed by viremic spread to multiple sites throughout the body. Incubation period varies from 14-21 days. ${ }^{20}$

The mechanisms by which the rubella virus causes fetal damage are poorly understood. Before the development of the maternal immune response, the virus spreads through the bloodstream and may affect multiple maternal tissues, including the placenta. Examination of damaged tissue suggests at least two possible mechanisms for the rubella cytopathology: a direct cytopathic effect, which may involve rubella virus-induced apoptosis and a virus-induced inhibition of cell division. ${ }^{21}$

Vascular injury and resulting insufficiency are more important in the pathogenesis of CRS. ${ }^{22}$ Placental infection that occurs during maternal viraemia, causes focally distributed necrotic areas in the chorionic villae epithelium and in the endothelial cells of its capillaries. These cells seem to be desquamated into the lumen of vessels, suggesting that rubella virus is transported into the fetal circulation as infected endothelial cell emboli, which may result in infection and damage of fetal organs. In general, affected organs are hypoplastic. ${ }^{23}$

Rubella virus particles may be retained in secluded sites such as the crystalline lens and virus antigens may persist in various target organs with recurrent periods of increased virus production and replication. The rubella virus can be isolated from the cerebrospinal fluid, urine and nasopharyngeal secretions in CRS infants and it may persist for up to 1 year of age in severely affected infants. ${ }^{24}$ 


\section{Teratogenecity}

The outcome of fetal infection is dependent on the gestational timing of maternal rubella, but fetal infection can occur at any stage of pregnancy. Infection occurring in the first 12 weeks of pregnancy causes congenital rubella infection in $90 \%$, with almost a $100 \%$ risk of congenital defects. From 13 to 17 weeks the risk of infection is about $60 \%$, and risk of defects about $50 \%$. From 18 to 24 weeks the risk of infection is about $25 \%$, with hardly any risk of congenital defects. ${ }^{25}$ In maternal infection after the first trimester, the frequency and severity of fetal damage decreases strikingly because the fetus is protected by the progressive development of fetal humoral and cell-mediated immune responses and by passive transfer of maternal antibodies. ${ }^{26}$ Also by this time the important phase of organogenesis is mostly complete. $^{22}$

\section{Host defenses}

During the first trimester, the fetus is incapable of a normal immune response and instead relies on maternal immunoglobulin G (IgG) antibodies transferred from the mother across the placenta. Unfortunately, at this early stage of development, placental transfer appears to be inefficient and fetal blood levels of IgG are only $5 \%$ to $10 \%$ of those in maternal serum. ${ }^{26}$

During the second trimester, the fetus starts to produce its own antibodies to launch both a humoral and cytotoxic response to the rubella virus. With the combination of its own antibodies and the continued transferred maternal IgG to the fetus, the fetus can largely protect itself from viral damage, although it is incapable of getting rid of the virus completely. ${ }^{26}$

The predominant class of fetal antibody produced in the latter half of pregnancy is IgM, although fetal IgG and IgA are also produced. Nevertheless, rubella specific IgG is more abundant overall, due to the combined amounts of both maternal and fetal antibody of this class. As the concentrations of maternal IgG decline following birth, rubella specific $\operatorname{IgM}$ will predominate for a period of several months before declining to levels that are lower than those of the increasing neonatal IgG. Virtually, all congenitally infected infants have detectable IgM during 3-6 months of life; and about one-third have detectable IgM from 6 months to 2 years of age. Over that first several years of life, the amounts of rubella specific IgG can decrease and some children can lose detectable $\mathrm{IgG}$ altogether. Low avidity IgG can persist even after disappearance of rubella virus specific IgM. ${ }^{2,27}$

\section{Systemic manifestation}

According to a global review of CRS sequelae, among infants with CRS, 60\% had hearing impairment, $45 \%$ congenital heart disease, $27 \%$ microcephaly, $25 \%$ cataract, $23 \%$ low birth weight, $19 \%$ hepatosplenomegaly, $17 \%$ purpura, $13 \%$ mental retardation, and $10 \%$ meningoencephalitis. In addition, hepatitis, myocarditis, bone lesions, dental defects, hypospadias, cryptorchidism, inguinal hernia, interstitial pneumonitis, cerebral calcification, insulin-dependent diabetes, thyroid dysfunction have also been reported. ${ }^{26}$ Therefore, congenital rubella is a chronic disease capable of producing ongoing vital organ damage throughout life.

The CRS consists of the classic triad of cataracts, sensorineural hearing loss and congenital heart disease. ${ }^{20}$ The embryo genetic time-table indicates that the most rapid development of heart muscle occurs at much the same time that the inner ear and lens are developing. Therefore damage to the ears and eyes is often accompanied by a variety of heart defects. ${ }^{26}$

\section{Cardiovascular manifestations}

Cardiac abnormalities are classic findings in infants with CRS with approximate incidence of $65 \%$. The most common cardiovascular lesions are patent ductus arteriosus followed by stenosis of the pulmonary artery and its branches. ${ }^{26,28,29}$ The next common heart defect is septal defects. However, a wide variety of cardiac malformations may be produced, such as stenosis of aortic valves, Fallot's tetralogy, coarctation of the aorta, tricuspid atresia and transposition of the great vessels and stenosis of other systemic vessels. ${ }^{30,31}$ 


\section{Ocular manifestations}

The ocular pathologies most commonly observed with CRS are nuclear cataracts, microphthalmia, and pigmentary retinopathy. Cataract is the most common ocular complication of CRS and often, the cataract is unilateral. Strabismus and nystagmus may also be seen in individuals with CRS. ${ }^{32}$

\section{Hearing defect}

Sensorineural deafness, which can progress after birth, is the most common rubella-associated defect. It is likely that the virus gains access to the inner ear through the blood supply of the stria vascularis. Examination of fetuses and neonates after rubella infection showed damage to the epithelium of the cochlear duct and the stria vascularis. ${ }^{26}$

\section{Brain damage}

Brain damage only occurs after rubella infection in the first 16 weeks of gestation, causing mild to severe mental retardation with spastic diplegia. Gross structural malformations are rare; instead, there is ischemic damage and variable microcephaly. Persistence of the virus in the cerebrospinal fluid may be associated with meningoencephalitis and cerebral vasculitis postnatally. ${ }^{26}$

\section{Fetal growth inhibition}

A constant feature of CRS is fetal growth retardation, perhaps due to reduced or slower cell division in infected cells. ${ }^{26}$

\section{Laboratory diagnosis}

Diagnostic tests used to confirm CRS include serologic assays and isolation of the virus.

\section{Virus isolation}

Rubella virus can be isolated from nasal, blood, throat, urine, and cerebrospinal fluid specimens from rubella and CRS cases (best results come from throat swabs). Infants with CRS should be considered infectious until 2 cultures of clinical specimens obtained 1 month apart are negative for rubella virus. Virus can be isolated by reverse transcription polymerase chain reaction (RT- PCR, real-time RT-PCR) and molecular typing. ${ }^{33}$

\section{Serologic testing}

The widely available serologic tests for laboratory confirmation of CRS infections are Enzyme Linked Immunosorbent Assay (ELISA) and Immunofluorescent Antibody (IFA) assay. ${ }^{33}$

\section{Prenatal diagnosis}

Detection of rubella virus RNA, protein in chorionic villus sampling and amniotic fluid has been currently demonstrated for prenatal diagnosis. ${ }^{34}$

\section{Treatment}

There is no specific antiviral therapy. Patients with congenital rubella require supportive care not only in the neonatal period but also throughout life for such permanent impairments as deafness and heart defect. Interferon and amantadine have been used in individual cases of CRS. Again isoprinosine has been administered with indeterminate results to patients with progressive rubella panencephalitis but has no apparent therapeutic benefit. ${ }^{20}$ Early diagnosis of CRS facilitates early intervention for specific disabilities like hearing impairment and congenital heart disease. ${ }^{33}$

\section{Preventing transmission from infants with CRS}

Infants with CRS can shed the virus for prolonged periods of time, up to 1 year of age or longer in some cases. Persons having contact with infants with CRS should be immune to rubella. Infants with CRS should be placed in contact isolation. These precautions should be enforced during any admission before the first birthday, unless two cultures of throat and urine specimens obtained 1 month apart are negative for virus after age 3 months. ${ }^{35}$ 


\section{Immunization}

The World Health Organization (WHO) has advocated the use of rubella vaccines in many countries recognizing the fact that CRS is a cause of preventable morbidity. The universal immunization of infants with vaccination of adolescent girls and adult women is the most effective approach to eliminate rubella and CRS. ${ }^{36}$ Rubella vaccine was introduced nationwide in 130 countries by the end of 2011, up from 83 countries in $1996 .{ }^{37}$ The recommended vaccine is a live attenuated viral rubella vaccine - given by the intramuscular or subcutaneous route as monovalent, MR (measles-rubella) or MMR (mumps-measles-rubella). ${ }^{38}$

The WHO established goals to eliminate rubella and CRS in the WHO Region of the Americas by 2010 and the WHO European Region by 2015. Sustained vaccination strategy enabled America to decrease rubella cases by $98 \%$, from 1998 to 2006 . Consequently, the CRS incidence had also decreased worldwide. ${ }^{39}$ Bangladesh officially launched measles-rubella (MR) vaccine on 26th September, 2012 as part of its routine immunisation programme to prevent rubella infections. The vaccine is being introduced in place of the only-measles vaccine to children aged 9 months. A second-dose of measles vaccine is recommended for children at any time between 15 and 18 months of age. Girls aged 15 will get the vaccine when they turn up at the Expanded Programme on Immunisation (EPI)'s outreaches for the first dose of tetanus (TT). ${ }^{40}$

\section{Surveillance}

In addition to appropriate vaccination with good coverage, adequate surveillance of CRS is needed to ensure continued control. Surveillance data are used to identify groups of persons or areas in which disease control efforts (such as immunization) can reduce disease incidence and to evaluate the effectiveness of disease prevention programmes and policies.

In 2009, out of 193 WHO member states, 123 states were reporting CRS and a total of 165 CRS cases were reported. ${ }^{36}$ While surveillance data on
CRS from most developed countries is available, statistics from most developing countries including Bangladesh is lacking.

\section{Recommendations}

CRS is a preventable disease. Prompt detection of CRS can further reduce CRS related childhood mortality and morbidity. Therefore, general practitioners, neonatologists, paediatricians and health workers must be aware to identify the CRS cases and should refer to specialized institutes as early as possible. Women who contract rubella while pregnant should be monitored for birth outcome, and a rubella-specific IgM antibody test should be performed on the infant after birth. Surveillance for CRS should be implemented. Pediatric specialized centres caring for children with mental retardation, congenital heart defects, congenital deafness and hearing impairment, congenital cataracts, and growth retardation may be a source of surveillance. ${ }^{34}$

\section{Conclusion}

Congenital rubella syndrome is a devastating condition that has multiple consequences for any society, both medical and financial. To date, preventative strategies have made large differences, but there is still much more work to be done. To eliminate CRS and to reduce CRS related morbidities, it is crucial to ensure mass immunization, monitor the magnitude of the disease and arrange rehabilitative services.

\section{References}

1. Burchett SK. Viral Infections. In: Cloherty JP, Eichenwald EC, Stark AR, editors. Manual of Neonatal Care. 5th ed. Philadelphia: Lippincott Williams and Wilkins; 2004. p.282-85.

2. Robertson SE, Featherstone DA, Gacic-Dobo M, Hersh BS. Rubella and Congenital Rubella Syndrome: Global Update. Rev Pam Salud Publica. 2003;14(5):306-15.

3. Klein JO, Remington JS. Current Concepts of Infections of the Fetus and Newborn Infant. In: 
Remington JS, Klein JO, editors. Infectious Disease of the Fetus and Newborn Infant. Philadelphia: Saunders; 1995. p.1-19.

4. O'Neill JF. The Ocular Manifestations of Congenital Infection: A Study of the Early Effect and Long-Term Outcome of Maternally Transmitted Rubella and Toxoplasmosis. Trans Am Ophthalmol Soc. 1998;96:813-79.

5. Freij BJ, Sever JL. Chronic Infections. In: Avery GB, Fletcher MA, Macdonvld MG, editors. Neonatology: Pathophysiology and Management of the Newborn. Philadelphia: Lippincott; 1994. p.1029-82.

6. Robert S, Duszak OD. Congenital Rubella Syndrome - Major Review. Optometry. 2009;80:36-43.

7. Rakowsky A, Sever JL. Rubella (German measles). In: Gorbach SL, Barlett JG, Blacklow NR, editors. Infectious Diseases. Philadelphia: Saunders; 1998. p.1301-11.

8. Achievements in Public Health: Elimination of Rubella and Congenital Rubella Syndrome - United States, 1969-2004, Centers for Disease Control and Prevention (CDC). MMWR. 2005;54(11):279-82.

9. Lindergren ML, Fehrs LJ. Hadler SC. Update: Rubella and Congenital Rubella Syndrome, 1980-1990. Epidemiol Rev. 1991;13:341-48.

10. Tookey P. Rubella in England, Scotland and Wales. Euro Surveill. 2004;9(4):21-22.

11. Arnold JK. Ocular Manifestations of Congenital Rubella. Curr Opin Ophthal. 1995;6:45-50.

12. Chua KB, Lam SK, Hooi PS, Chua BH, Lim CT. Retrospective Review of Serologic Rubella Activity in University Hospital Kuala Lumpur. Med J Malaysia. 2000;55(3):299-303.

13. Juma AH. Infantile Rubella Cataract in Oman. Medical Newsletter (Oman). 1988;6(1):27-28.

14. Guanasekera DP, Guanasekera PC. Rubella Immunization-Learning from Developed Countries. Lancet. 1996;347:1694-95.

15. Kyaw ZT, Win MO, Thein TM, Than NS, Aye MH, Khin MA, et al. Active Surveillance for Congenital Rubella Syndrome in Yangon, Myanmar. Bull World Health Organ. 2006;84:12-20.
16. Banatvala JE. Rubella - Could Do Better. Lancet. 1998;358:849-50

17. Diorditsa S. Who Global Measles and Rubella Management Meeting Progress and Challenges in Bangladesh. WHO HQ Measles Cases in Bangladesh by Year 2003-2010; 2011 March 15-17; Geneva: 2011 [cited 2013 Jun 03]. Available from: http://www.measlesrubellainitiative.org/wpcontent/uploads.

18. Imam H, Yasmin M, Ahsan CR, Nessa J. Pregnant Women in and around Dhaka City: are Their Children at Risk of Developing Congenital Rubella Syndrome? Indian Journal of Microbiology. 2010;50(4):443-48.

19. Sadighi J, Eftekhar H, Mohammad K. Congenital Rubella Syndrome in Iran. BMC Infectious Diseases. 2005;5:44.

20. Hussain M N. Congenital Rubella Syndrome. Professional Med J. 2006;13(1):11-16.

21. Lee JY, Boden DS. Rubella Virus Replication and Links to Teratogenicity. Clin Microbiol Rev. 2000;13(4):571-87.

22. Miller E, Cradock-Watson JE, Pollock TM. Consequences of Confirmed Maternal Rubella at Successive Stages of Pregnancy. Lancet. 1982;2:781-84

23. Banatvala JE, Bron DW. Congenital Rubella Syndrome as a Systemic Infection. Studies of Affected Infants Born in Philadelphia, U.S.A. Lancet. 2004;363:1127-37.

24. Frij BJ, South MA, Sever JL. Maternal Rubella and the Congenital Rubella Syndrome. Clin Perinatol. 1988; 15:247-57.

25. Deka D. Diagnosis of Acute Rubella Infection during Pregnancy. J Obstet Gynaecol India. 2006;56(1):44-46

26. Webster WS. Teratogen Update: Congenital Rubella. Teratology. 1998;58:13-23.

27. Corcoran C, Hardie DR. Serologic Diagnosis of Congenital Rubella: A Cautionary Tale. Pediatr Infect Dis J. 2005;24(3):286-87.

28. Zimmerman L, Reef SE. Incidence of Congenital Rubella Syndrome at a Hospital Serving a Predominantly Hispanic Population, El Paso, Texas. Pediatrics. 2001;107:11-14. 
29. Cusco D, Arequipa A. Congenital Rubella Syndrome in 6 Schools for Deaf and/or Blind Children in Lima, Peru, 1998-2000. Anales de la Facultad de Medicina. 2002;63:93-100.

30. Agarwal R. Letters to the Editor. A Case Report of CRS in a Teenage Girl. Indian Pediatrics. 2001;38:1333-35.

31. Quimtana EM, Gonalez FR, Rionda PJ. Congenital Rubella Syndrome and Left Pulmonary Artery Sling. ERJ. 2012;39(2):495-96.

32. Arnold JJ, Mcintosh EG, Martin FJ. A Fifty Year Follow up of Ocular Defects in Congenital Rubella: Late Ocular Manifestations. Aust NZ J Ophthalmol. 1994;22:1-6.

33. Zimmerman L, Reef SE. VPD Surveillance Manual, 3rd edition, Chapter 12: Congenital Rubella Syndrome; 2002:12-16.

34. Neto EC, Rubin R, Schulte J, Giugliani R. Newborn Screening for Congenital Infectious Diseases. Emerg Infect Dis. 2004;10(6):1068-73.

35. CDC. Control and Prevention of Rubella: Evaluation and Management of Suspected Outbreaks, Rubella in Pregnant Women and Surveillance for Congenital Rubella Syndrome. MMWR Recomm Rep. 2001;50:1-23.
36. Progress toward Control of Rubella and Prevention of Congenital Rubella Syndrome - Worldwide, 2009, Centers for Disease Control and Prevention (CDC). MMWR Morb Mortal Wkly Rep. 2010;59:1307-10.

37. unicef.org [Internet]. Global Immunization Data [2012; cited 2015 May 10]. Available from: http://www.unicef.org/videoaudio/PDFs/Global_Im munization_Data_\%282011_Data\%29.pdf.

38. who.org [Internet]. Immunization, Vaccines and Biologicals [updated 2015 April 9; cited 2015 May 10]. Available from: http://www.who.int/ immunization_monitoring/diseases/rubella/en/index .html.

39. Castillo SC, Marsigli C, Bravo AP, Flannary B, Ruiz MC, Tambini G. Elimination of Rubella and Congenital Rubella Syndrome in the Americas. J Infect Dis. 2011;204:571-8.

40. bdnews24.com [Internet]. Measles-Rubella Vaccine Launched [updated 2012 September 26; cited 2015 May 10]. Available from:http://bdnews24.com/ health/2012/09/26/Measles-Rubella-VaccineLaunchd. 